\title{
Glycogenolysis Inhibition
}

National Cancer Institute

\section{Source}

National Cancer Institute. Glycogenolysis Inhibition. NCI Thesaurus. Code C40640.

Glycogenolysis Inhibition involves interference with, or restraint of, the activities of biologic molecules or complexes involved in the breakdown of glycogen to glucose by hydrolysis or phosphorolysis. 